ACCEPTED MANUSCRIPT

\title{
Preservation over time of dried acellular esophageal matrix
}

To cite this article before publication: Giovanni Giuseppe Giobbe et al 2018 Biomed. Phys. Eng. Express in press https://doi.org/10.1088/20571976/aae4ff

\section{Manuscript version: Accepted Manuscript}

Accepted Manuscript is "the version of the article accepted for publication including all changes made as a result of the peer review process, and which may also include the addition to the article by IOP Publishing of a header, an article ID, a cover sheet and/or an 'Accepted Manuscript' watermark, but excluding any other editing, typesetting or other changes made by IOP Publishing and/or its licensors"

This Accepted Manuscript is (C) 2018 IOP Publishing Ltd.

During the embargo period (the 12 month period from the publication of the Version of Record of this article), the Accepted Manuscript is fully protected by copyright and cannot be reused or reposted elsewhere.

As the Version of Record of this article is going to be / has been published on a subscription basis, this Accepted Manuscript is available for reuse under a CC BY-NC-ND 3.0 licence after the 12 month embargo period.

After the embargo period, everyone is permitted to use copy and redistribute this article for non-commercial purposes only, provided that they adhere to all the terms of the licence https://creativecommons.org/licences/by-nc-nd/3.0

Although reasonable endeavours have been taken to obtain all necessary permissions from third parties to include their copyrighted content within this article, their full citation and copyright line may not be present in this Accepted Manuscript version. Before using any content from this article, please refer to the Version of Record on IOPscience once published for full citation and copyright details, as permissions will likely be required. All third party content is fully copyright protected, unless specifically stated otherwise in the figure caption in the Version of Record.

View the article online for updates and enhancements. 


\section{Preservation Over Time of Dried Acellular Esophageal Matrix}

Giovanni G. Giobbe ${ }^{\mathrm{a}, \mathrm{b}, 1}$, Alessandro Zambon ${ }^{\mathrm{b}, \mathrm{c}, 1, *}$, Massimo Vetralla ${ }^{\mathrm{b}, \mathrm{c}}$, Luca Urbani ${ }^{\mathrm{a}, \mathrm{d}, \mathrm{e}}$, Koichi

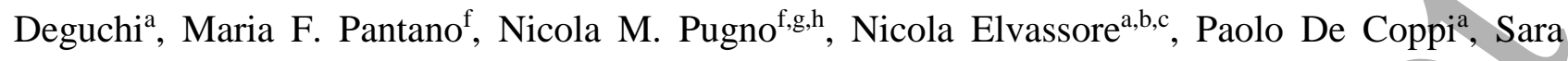
Spilimbergo ${ }^{\mathrm{b}, *}$

${ }^{a}$ Stem Cells and Regenerative Medicine, Great Ormond Street Institute of Child Health, University College London, 30 Guilford Street, WC1N 1EH London, United Kingdom

${ }^{\mathrm{b}}$ Department of Industrial Engineering, University of Padova, via Marzolo 9, 35131 Padova, Italy

${ }^{c}$ Venetian Institute of Molecular Medicine, Via Orus Giuseppe 2, 35129 Padova, Italy

${ }^{\mathrm{d}}$ Institute of Hepatology London, Foundation for Liver Research, 111 Coldharbour Lane, SE5 9NT London, United Kingdom

${ }^{\mathrm{e}}$ Faculty of Life Sciences \& Medicine, King's College London, London, United Kingdom

${ }^{\mathrm{f}}$ Laboratory of Bio-inspired \& Graphene Nanomechanics, Department of/Civil, Environmental and Mechanical Engineering, University of Trento, Via Mesiano 77, I-38123 Trento, Italy

${ }^{\mathrm{g}}$ Ket Lab, Edoardo Amaldi Foundation, Italian Space Agency, Via del Politecnico snc, 00133 Rome, Italy

${ }^{\mathrm{h}}$ School of Engineering and Materials Science, Queen Mary University of London, Mile End Road, E1 4NS London, United Kingdom

*corresponding authors

sara.spilimbergo@ unipd.it FAX +390498275461 TEL +390498275466

alessandro.zambon@unipd.it FAX +390498275461 TEL +390498275472

${ }^{1}$ these authors equally contributed to this work 


\begin{abstract}
Preservation of acellular matrices represents a big challenge for the improvement of tissue engineering. In this work, a new method to preserve over time a decellularized esophageal scaffolds was explored. Dried and sterile acellular esophagi were obtained with a combined treatment of ethanol and a subsequent supercritical $\mathrm{CO}_{2}$ drying. Preservation of the extracellular matrix architecture, collagen content, and mechanical properties up to 6 months demonstrated the efficiency of the methodology with implications in natural scaffold storage. In vitro support of mesenchymal stem cells showed a promising indication to the further use of the technology in preclinical and clinical application.
\end{abstract}

KEYWORDS: dry decellularized scaffold; tissue storage; esophageal replacement; supercritical $\mathrm{CO}_{2}$ drying; extracellular matrix preservation; tissue engineering; mesenchymal stem cells. 


\section{INTRODUCTION}

Several congenital and acquired conditions may require surgical esophageal replacement. Esophageal atresia (EA) is the most common congenital anomaly of the esophagus [1], while malignant conditions such as leiomyosarcoma, teratoma and inflammatory pseudo tumor predominate in the adult population [2]. Esophageal cancer is the eighth most common cancer in the world, with 456000 new diagnosed cases and 40000 deaths in 2012 [3]. The two main histological types of esophageal cancer are adenocarcinomas and squamous cell carcinomas sub-types which have a significant heterogeneity in incidence, geographic distribution, ethic pattern and etiology [4]. Despite modern therapies overall 5-years survival rates range from 15 to $30 \%$ [5-7]. Current choices for esophageal replacement involve the use of more distal parts of the gastrointestinal tract such as stomach, jejunum and colon, with long-term problems associated to each technique [8]. Tissue engineering offers valid alternative to conventional transplantation by replacing artificial tissue or organ function with constructs that contain specific populations of living cells [9]. Specifically, patients with esophageal severe disorders would have a great advantage from tissue-engineered esophagi used in replacement therapies.

Several esophageal scaffolds have been proposed for tissue engineering: synthetic scaffolds, naturally derived scaffolds and natural acellular matrix [10]. Some experiments with synthetic scaffolds have led to good results in animal models $[11,12,13]$. Natural collagen scaffolds showed promising outcomes in the past years $[14,15]$. Decellularized esophageal scaffolds proved to be a valuable resource for clinical translation [16,17]. Natural acellular matrices are derived from human and animal organs or tissues that have been treated to remove cells and immunogenic material. They retain the architecture of the tissue of origin and also the molecular components of the native extracellular matrix (ECM). Our group previously demonstrated how a pig esophagus can be efficiently decellularized while maintaining defined ultrastructure, which is essential for medical applications [18]. 
One of the major drawbacks of tissue engineered organs is the difficulty to preserve and store decellularized scaffolds in a highly sterile condition, which is essential in the perspective of clinical use. We recently published a work were we showed the possibility to cryopreserve rabbit esophagi which maintain proper ECM structure and function [19]. Considering scaffold preservation for cell repopulation and transplant, there is the necessity to move from simple cellular cryobiology to other more sophisticated techniques valid for whole bigger organs.

Not all sterilization methods can be used with tissue-engineered scaffolds. Flame, steam or heat at 121 or $136{ }^{\circ} \mathrm{C}$ cannot be applied to biological tissues. Other methods, such as chemical sterilization with molecules like paracetic acid or ethylene oxide have been found to alter mechanical properties of the tissues or leave possible toxic residuals within the ECM [20,21]. One of the most commonly used method for sterilization in tissue engineering is the ionizing radiation. Gamma irradiation has been shown to increase stiffness and strength at dosage lower than $15 \mathrm{kGy}$, while mechanical properties decrease at higher dosages [22]. Ionizing radiation has been shown to also induce structural changes to the ECM proteins [23,24], which can eventually alter and compromise cell adhesion capacity [25].

Supercritical carbon dioxide $\left(\mathrm{SC}-\mathrm{CO}_{2}\right)$ has been widely applied to the sterilization of pharmaceuticals and foods. SC- $\mathrm{CO}_{2}$ has been used as a method to decellularize tissues [26] and more recently it has been investigated as a method for sterilization of biological scaffolds in combination with additive [27]. The process works at low temperatures $\left(30-35^{\circ} \mathrm{C}\right)$ which do not compromise biological molecules, and leaves no cytotoxic residuals, essential in perspective of cell repopulation. $\mathrm{SC}-\mathrm{CO}_{2}$ has been recently applied to the sterilization of soft decellularized tissues such as the aortic valve and portions of lung tissue $[28,29]$. We recently developed a method that combines ethanol and $\mathrm{SC}-\mathrm{CO}_{2}$ to dry esophageal decellularized tissue, which allows to maintain physiological and mechanical properties and biocompatibility for cell repopulation [30].

Our aim is to explore the capacity of the ethanol/SC-CO 2 method to sterilize a decellularized swine esophagus as well as the conservation over time of this tissue for clinical application. 


\section{MATERIALS AND METHODS}

\section{Organ harvest}

Esophagi were collected from white domestic piglets (Sus scrofa domesticus), 12 to 16 weeks-old, from 25 to $40 \mathrm{~kg}$ in weight. Piglets were euthanized by administration of an overdose of intravenous Sodium Pentobarbital (Sigma Aldrich). The esophagus was harvested with a midline incision, and thoroughly washed with phosphate buffer solution (PBS, Thermo Fisher) with 5\% antibiotic antimycotic solution (Thermo Fisher). All surgical procedures and animal handling were carried out in accordance with UK Home Office guidelines under the Animals (Scientific Procedures) Act 1986 and the local ethics committee.

\section{Tissue decellularization}

Esophageal decellularization was performed with detergent enzymatic treatment (DET) following a previously published procedure [18]. Briefly, the lumen was continuously perfused by three subsequent cycles of DET using a variable speed roller pump (Masterflex L/S, Cole-Parmer) at 0.6 $\mathrm{ml} / \mathrm{min}$. Three subsequent solutions were used for each cycle: MilliQ water at $4^{\circ} \mathrm{C}$ for $18 \mathrm{~h}, 4 \%$ sodium deoxycholate at room temperature for $4 \mathrm{~h}$, and 50 Kunitz units DNase I in $1 \mathrm{M} \mathrm{NaCl}$ solution (all from Sigma Aldrich) at room temperature for $3 \mathrm{~h}$. Samples were washed, divided into cylindrical segments, and stored in sterile PBS at $4^{\circ} \mathrm{C}$ until use.

\section{Supercritical $\mathrm{CO}_{2}$ drying}


The carbon dioxide supercritical drying process $\left(\mathrm{SC}-\mathrm{CO}_{2}\right)$ was performed as previously reported [30]. Briefly, the samples were dehydrated by submersion in a series of ethanol (Sigma Aldrich) solutions $(50 \%-75 \%-95 \%-99.8 \%)$ for $20 \mathrm{~min}$ at each dilution. Then, samples were $\mathrm{CO}_{2}$ treated at $35^{\circ} \mathrm{C}$ and $10 \mathrm{MPa}$ for 90 minutes. A high pressure sapphire window cell (Separex S.A.S.) was used to carry out the experiments. The internal temperature and pressure were set with a thermostatic bath and an HPLC pump (Gilson 25SC). $\mathrm{CO}_{2}$ (purity 99.990\%, Messer) was flowed into the reactor at a constant flow rate of $23 \mathrm{ml} / \mathrm{min}$ until $10 \mathrm{MPa}$, then the pressure was maintained constant by tuning on a micrometric valve. To avoid any microbial contamination during the opening of the cell, a Bunsen burner flame was placed near the reactor chamber and the treated samples were collected with sterile tweezers in sterile tubes. The glass chamber was disinfected with EtOH after each sampling. Samples were vacuum packaged for storage in sterile plastic bag at $4^{\circ} \mathrm{C}$. Throughout the text $\mathrm{NT}$ and $\mathrm{T} \mathrm{t}_{0}$ refer to the control non-treated, and treated sample at time 0 ; $\mathrm{T}_{1}$ refers to the treated sample at 3 months from the process, $\mathrm{Tt}_{2}$ refers to the treated sample after 6 months from the process.

\section{Weight loss analysis}

Samples were weighted after ethanol and supercritical $\mathrm{CO}_{2}$ treatments with a precision scale (Ohaus Explorer). It was assumed that all weight loss observed was due to the moisture removal from the ECM. Weight reduction was expressed as the ratio of $\% \mathrm{~W}_{\text {end }} / \mathrm{W}_{\text {start, }}$, with $\mathrm{W}_{\text {end }}$ and $\mathrm{W}_{\text {start }}$ expressing respectively the weight of the sample before and after the treatment.

\section{Microbiological analysis}

Microbial load was analyzed before and after the treatment in terms of mesophilic bacteria, mesophilic spores, yeasts and molds by means of the standard plate count techniques as previously reported [31]. Serial dilutions in PBS were done with a weight ratio of 1:10. For the enumeration of mesophilic spores, the first dilution tubes were inserted in a thermostatic bath at $80^{\circ} \mathrm{C}$ for 10 
minutes before plating. Colonies of mesophilic bacteria and spores were counted after 72 hours incubation at $30^{\circ} \mathrm{C}$ on Plate Count Agar (Microbiol Diagnostici), while yeasts and molds were counted after $72-120$ hours at $25^{\circ} \mathrm{C}$ on dichloran rose-bengal chloramphenicol agar (DRBC, Biotec srl) plates. The enumeration was referred to the weight of initial product and expressed in colony forming units CFU/g. The degree of inactivation was calculated considering the $\log \left(\mathrm{N}_{\mathrm{N}} \mathrm{N}_{0}\right)$, where $\mathrm{N}_{0}(\mathrm{CFU} / \mathrm{g})$ and $\mathrm{N}(\mathrm{CFU} / \mathrm{g})$ is the number of CFU per gram in the untreated and treated sample, respectively. The quantification limit was $300 \mathrm{CFU} / \mathrm{g}$ for the agar pour plates, and $2000 \mathrm{CFU} / \mathrm{g}$ for the DRBC spread plates, while the limit of detection was $<10 \mathrm{CFU} / \mathrm{g}$ for the pour plate and $<100$ $\mathrm{CFU} / \mathrm{g}$ for the spread plates.

\section{Mechanical characterization}

Tensile tests were performed with a Midi 10 electromechanical testing machine (Messphysik Materials Testing). Before testing, the dried samples were rehydrated for $24 \mathrm{~h}$ in PBS. Then, samples including both epithelium and muscle tissues were cut with scissors in a regular rectangular shape (with width of $4-5 \mathrm{~mm}$ and length of $10-20 \mathrm{~mm}$, depending on the size of the esophagus sample) and fixed to the loading frame through double adhesive tape at both ends. Esophageal samples were cut both in longitudinal and transversal direction. All analyses were performed at room temperature at least in triplicates and at a speed of $0.1 \mathrm{~mm} / \mathrm{s}$.

\section{Collagen quantification}

All collagen isoforms were quantified using a total collagen assay kit (QuickZyme Biosciences) according to manufacturer's instructions. Before starting the analysis, dried samples were rehydrated in PBS for $48 \mathrm{~h}$, to be comparable with non-dried decellularized scaffolds. Collagen standard $(1200 \mu \mathrm{g} / \mathrm{mL}$ in $0.02 \mathrm{M}$ acetic acid) was provided by the manufacturer. Briefly, representative decellularized esophageal samples of each group (untreated and supercritical $\mathrm{CO}_{2-}$ dried) were weighed and directly hydrolyzed in $6 \mathrm{M} \mathrm{HCl}$ at $95{ }^{\circ} \mathrm{C}$ for $20 \mathrm{~h}$. Samples were cooled to 
room temperature and centrifuged to remove debris. Supernatants were mixed with a chromogen reagent at $60^{\circ} \mathrm{C}$ for $1 \mathrm{~h}$ to detect hydroxyproline residues. Absorbance for each sample was determined at $555 \mathrm{~nm}$ using a microplate reader (Infinite 200 Pro Tecan).

\section{Cell culture and scaffold seeding}

Human bone marrow mesenchymal stem cells (hBMMSCs) were provided by the Cellfactory of Policlinico Hospital (Milan, IT). Cells were expanded in tissue culture T75 flask in MEM-alpha, 10\% Fetal Bovine Serum, 1\% Penicillin-Streptomycin (all from Thermo Fisher). At 80-90\% confluence, cells were detached with Trypsin-EDTA $0.25 \%$ (Thermo Fisher) and seeded in 48multiwell and on the decellularized scaffold. Only early passages of cells were used for the experiments (p4-p8). The dry decellularized scaffolds were rehydrated for 24h in PBS and mild agitation, then punched with $8 \mathrm{~mm}$ biopsy punches (B life) and washed twice in mem-alpha with the second wash incubated overnight at $37^{\circ} \mathrm{C}$ to equilibrate the tissue and avoid osmotic shock during cell seeding. Tissue disks were transferred to 48 multiwells with the luminal side up, and incubated with 300 $\mu \mathrm{L} /$ well of complete medium for $24 \mathrm{~h}$ at $37^{\circ} \mathrm{C}$ and $5 \% \mathrm{CO}_{2}$. For conditioned medium cytotoxicity experiments, $2 \times 10^{4}$ cells/well were seeded in $300 \mu \mathrm{L}$ of each conditioned medium and cultured for $48 \mathrm{~h}$. For cell adhesion experiments, $1.5 \times 10^{5}$ cells/disk were seeded and analyzed after $48 \mathrm{~h}$ of culture, and fixed after 10 days of expansion, with $1 \mathrm{~mL}$ fresh medium change every other day.

\section{Histological and fluorescence analyses}

Esophageal samples were fixed overnight in paraformaldehyde $4 \%$ at $4{ }^{\circ} \mathrm{C}$, then dehydrated with sucrose (Sigma Aldrich) serial passages $\left(10 \%-20 \%-30 \%, 12 \mathrm{~h}\right.$ each at $\left.4^{\circ} \mathrm{C}\right)$. Samples were then frozen by submersion in isopentane $\left(\mathrm{C}_{5} \mathrm{H}_{12}\right.$, Sigma Aldrich) cooled in a liquid nitrogen bath, and included in Optimal Cutting Temperature compound (OCT, Kaltech). Cryosections of $10 \mu \mathrm{m}$ were prepared onto Superfrost Plus slides (Thermo Fisher) using a cryomicrotome (Cryostat Leica CM1860). Tissue slides were stained with Haematoxylin and Eosin (H\&E), Masson's trichrome 
(MT) and Alcian blue (AB) stains (all from Bio-Optica), according to manufacturer's instructions. Cytochemistry analyses on tissue slices were performed using Alexa Fluor 488 Phalloidin (Thermo Fisher) 1:200 and Hoechst (Sigma Aldrich) $10 \mu \mathrm{M}$ diluted in PBS with 0.1\% Triton X-100 (Sigma Aldrich). Color and fluorescence images were obtained using a color camera mounted on fluorescence inverted microscope (Leica DMI4000).

\section{Cell vitality assay}

Cultured samples were analyzed with Live/Dead viability/cytotoxicity kit for mammalian cells (Thermo Fisher) according to manufacturer's instructions. Briefly, samples were washed with PBS twice. $2 \mu \mathrm{M}$ calcein $\mathrm{AM}$ and $2 \mu \mathrm{M}$ ethidium homodimer-1 were dissolved in basal medium (without serum), together with sterile $1 \mu \mathrm{M}$ Hoechst (Sigma Aldrich). Samples were incubated in Live/Dead solution for $45 \mathrm{~min}$ at $37^{\circ} \mathrm{C}$, then washed in basal medium and analyzed at fluorescence microscope, with $360 \mathrm{~nm}$ filter for Hoechst, $488 \mathrm{~nm}$ for calcein and $594 \mathrm{~nm}$ for EthD-1.

\section{RESULTS}

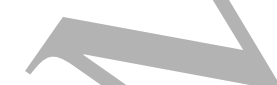

The first step was the decellularization of esophageal tissues obtained from euthanized piglets. Organs were harvested, washed, and the decellularization process was started within 12 hours from collection. Decellularized tissues were divided into portions to be processed with supercritical $\mathrm{CO}_{2}$ and stored at different time points, in triplicate for each condition. Tissues were stored without need for $\gamma$-irradiation after the dehydration procedure. At specific time points, tissues were rehydrated and analyzed (Fig. 1). 


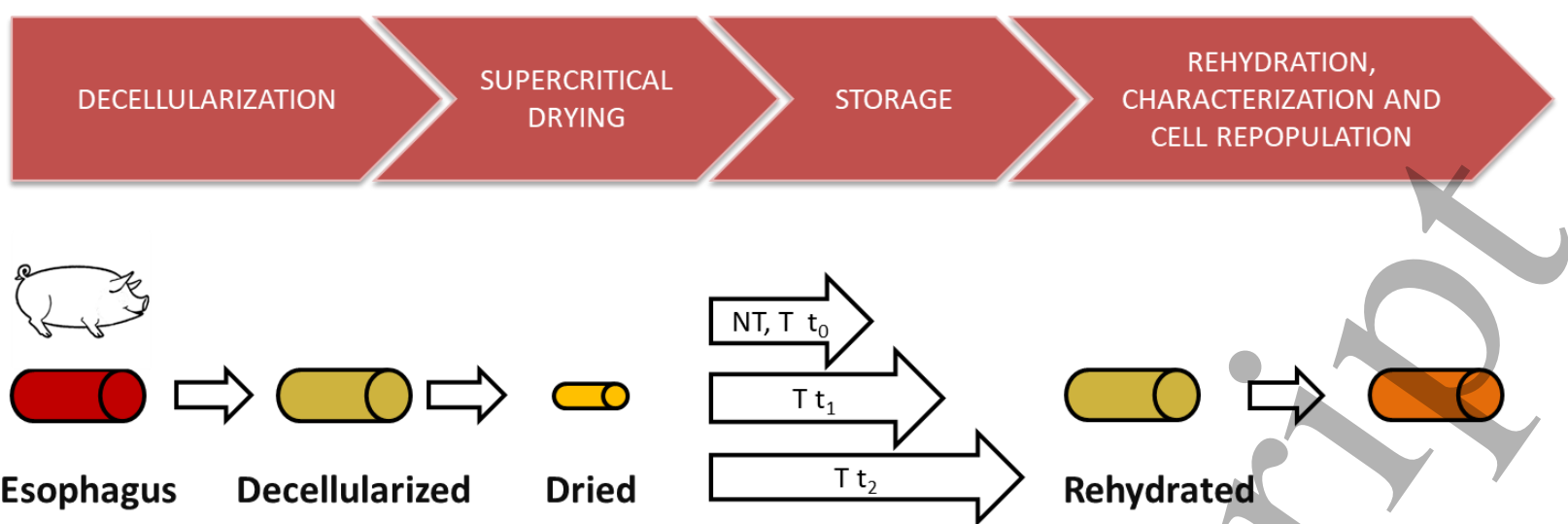

Figure 1: schematic overview of the long term tissue storage work strategy. NT and T t0 refer to the control nontreated, and treated sample at time $0 ; \mathrm{T} t 1$ refers to the treated sample at 3 months from the process, $\mathrm{T}$ t 2 refers to the treated sample after 6 months from the process.

The quality of the decellularization protocol to obtain esophageal tissue with absence of genetic material and cellular components was deeply investigated in our previous works $[18,19,30]$. The morphology of the tissue after rehydration process was comparable with freshly decellularized tissue (Fig. 2A) at all the time points (data not shown). The process of supercritical drying shows high loss in weight compared to ethanol dehydration, due to complete loss of water residual and ethanol in the ECM (Fig. 2B). We performed complete microbial inactivation test to assess whether the $\mathrm{CO}_{2}$ drying was able to reduce bacterial load compared to non-treated sample. Results were negative in all the contaminating agent categories analyzed (Fig. 2C), meaning that supercritical $\mathrm{CO}_{2}$ drying procedure has a high sterilization capacity.

A key feature of decellularized scaffolds for organ transplantation is the preservation of their mechanical properties, which must be comparable to those of the original tissue. We performed tensile tests in order to derive the strength and strain at break of dehydrated decellularized esophageal samples in longitudinal and transversal direction (Suppl. Fig. 1A). All the different storage time points were analyzed. Mechanical tests showed that treated samples have higher strength compared to control samples at $t_{0}$, especially along the longitudinal direction (Fig. 2D). Considering the strain at break, both longitudinal and transversal sections showed less variation 
between the non-treated samples and the dehydrated ones at different time points (Fig. 2E and Suppl. Fig. 1B). Some differences were expected because of the biological nature of the tested samples, which can cause significant variation in the mechanical behavior of samples even taken from the same esophagus. Furthermore, we can observe that both the strength and strain at break of treated samples do not vary significantly at different time points. Overall, non-treated controls and treated samples showed comparable mechanical properties, stating that storage over time of dehydrated scaffolds does not seem to affect physical characteristics of the matrix)(at these specific time points).

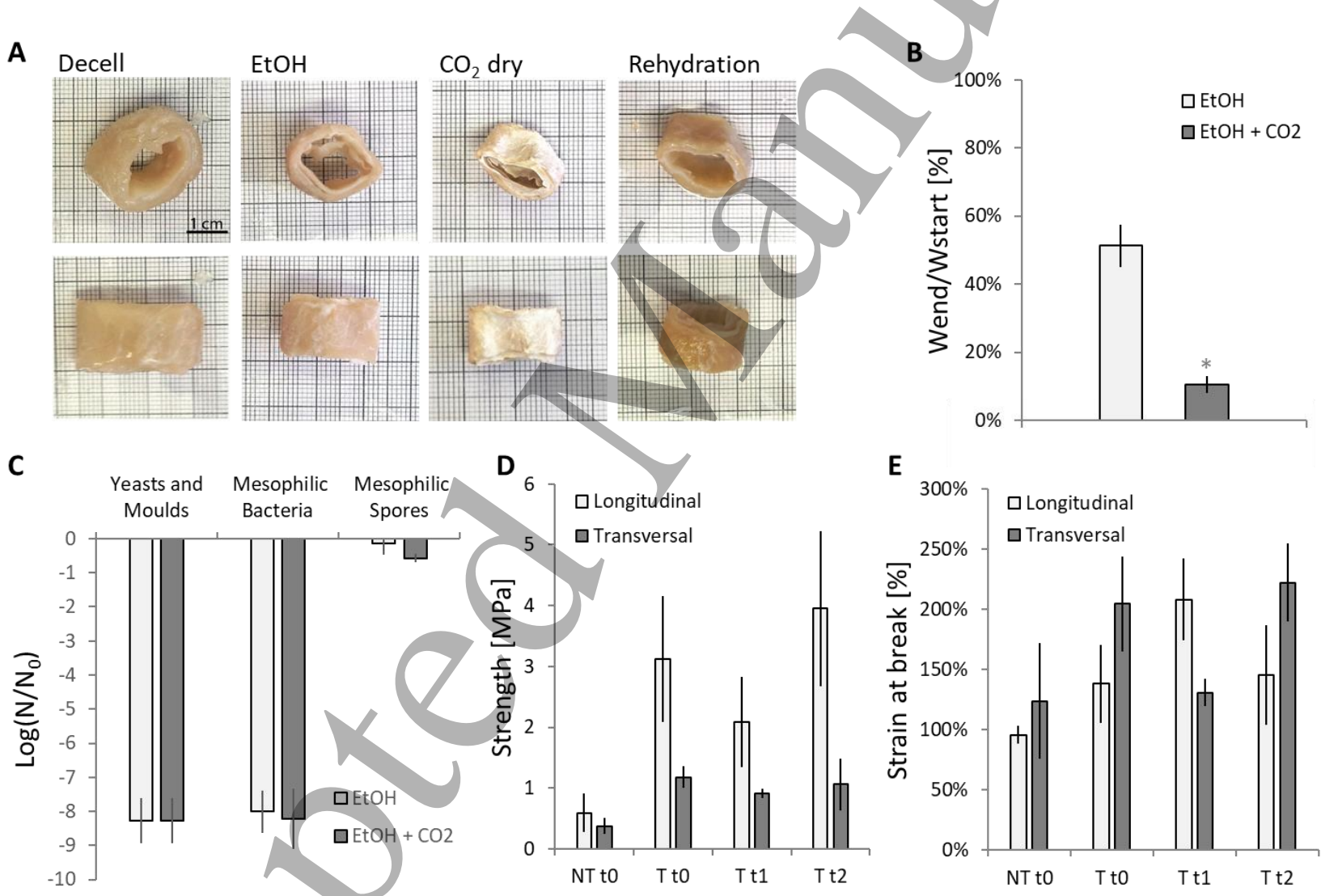

Figure 2: Supercritical $\mathrm{CO}_{2}$ drying effects. (A) Cylindrical sections of the decellularized esophagus at different steps of the process: Acellular (Decell); after 80 min dehydration in ethanol solution (EtOH); after supercritical $\mathrm{CO}_{2}$ drying $\left(\mathrm{CO}_{2}\right.$ dry); after $24 \mathrm{~h}$ rehydration in PBS (Rehydration). (B) Weight loss percentage after 80 min dehydration in ethanol, and after a following $90 \mathrm{~min}$ of supercritical $\mathrm{CO} 2$ drying at $100 \mathrm{bar}, 35^{\circ} \mathrm{C}$. (C) Microbial inactivation. Microbial reduction in terms of yeasts and molds, mesophilic bacteria and mesophilic spores after EtOH dehydration, and after the further $\mathrm{CO}_{2}$ drying. (D-E) Mechanical characterization. Strength [MPa] and strain at break [\%] for longitudinal and 
transversal samples at different storage time points. All data are shown as mean values of $\mathrm{n} \geq 3$ with St. Dev, t-tests $* \mathrm{P}$ $\leq 0.05$

To further assess the stability of the dehydrated decellularized scaffolds after long-term storage, staining and quantification for specific ECM components were performed. The quality of the decellularization process and the preservation of the esophageal architecture, previously demonstrated with our dehydration method [30] (Suppl. Fig. 2A-B) by the presence of the three esophageal layers, namely mucosa, submucosa and muscular layers, was also confirmed in all the analyzed samples by $H \& E$ staining (Fig. 3A). H\&E staining performed on non-treated and treated tissue sections at different time points showed the quality of the decellularization process and preservation of muscle ECM fiber structure (Fig. 3A). MT staining showed how keratin, muscle fiber structure and collagen were maintained in all the time points and conditions. Finally, AB staining revealed good preservation of glycosaminoglycans in the mucosa. These qualitative analyses prove that supercritical $\mathrm{CO}_{2}$ drying does not affect the quality of the ECM in decellularized scaffolds after long-term storage. To corroborate what evidenced with the staining, we quantified collagen in randomized portions of treated and untreated esophagi. Dried samples showed high preservation of all isoforms of collagens in all the time points, compared to nontreated samples (Fig. 3B). Collagen slight increase during time could be ascribed to a small loss in weight due to loss of other proteins, with consequent concentration of collagen in the scaffold (data frequently observed in literature [32,33]). 
A
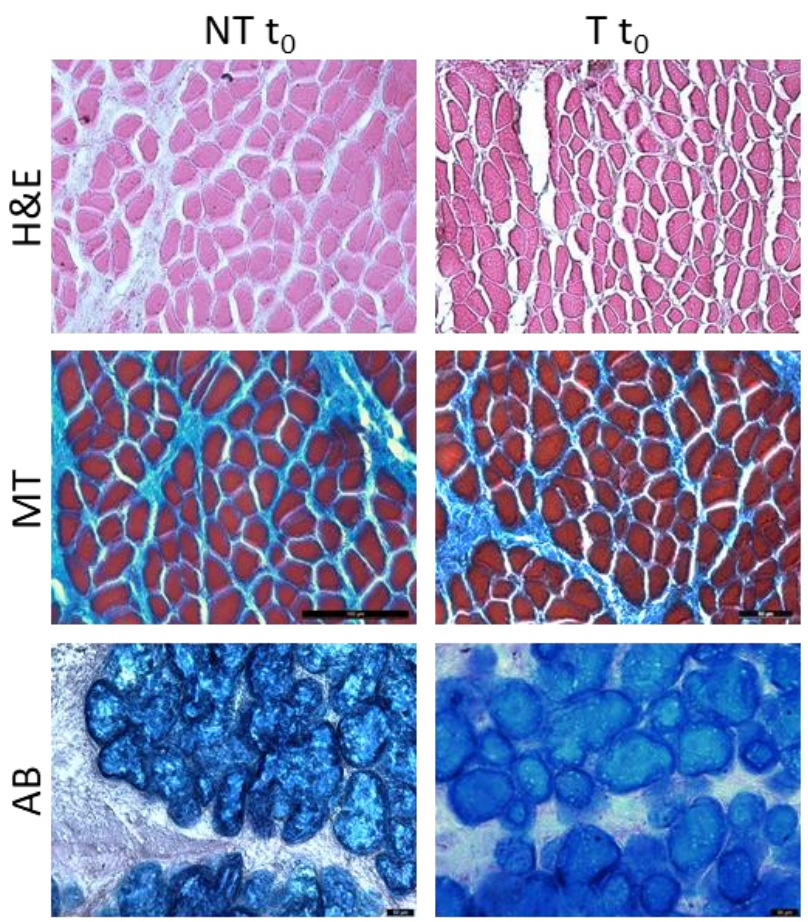

B

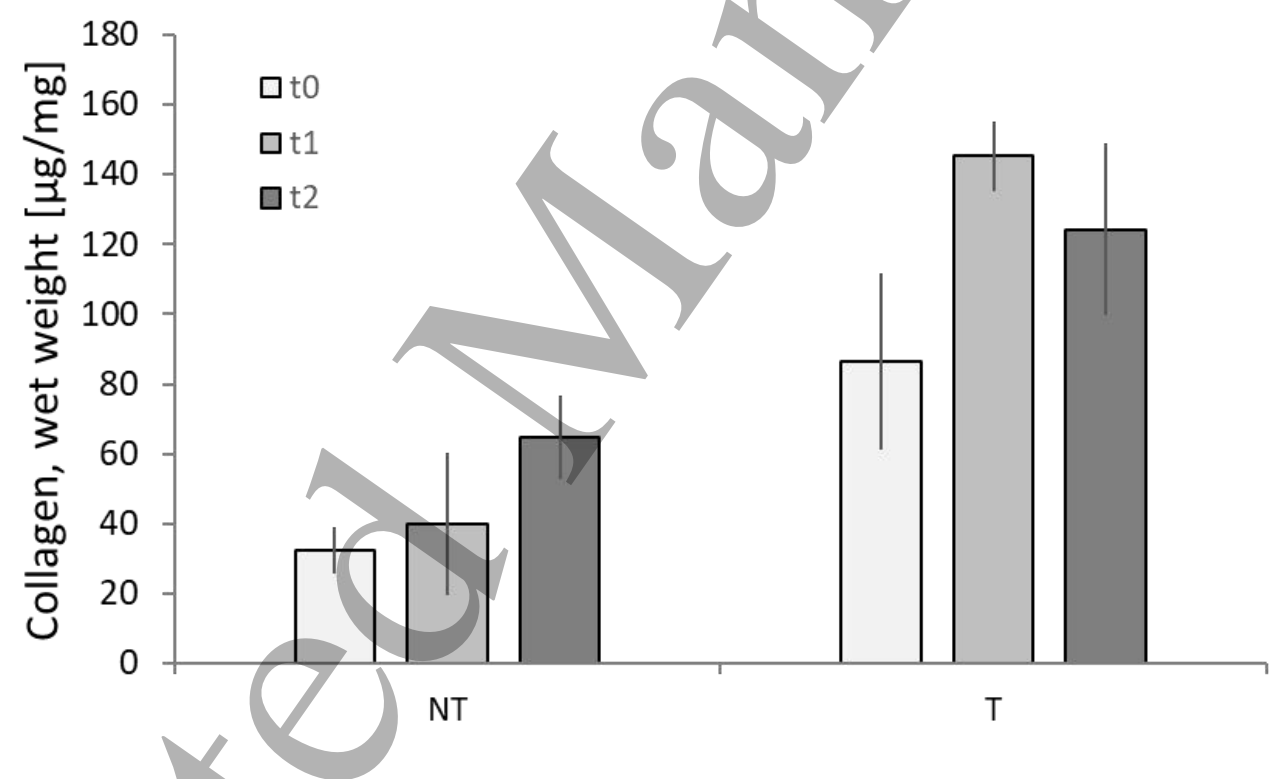

Figure 3: (A) Histological analysis. Hematoxylin and eosin staining (H\&E), Masson's trichrome (MT) and alcian blue (AB) at different storage times. H\&E shows the absence of residual pig cell nuclei (absence of dark blue dots), muscle fiber residual ECM shown in dark pink, while preserved collagen is in pale pink. MT shows red keratin and muscle fibers, and blue collagen, while light pink indicates cytoplasm and dark brown cell nuclei (both absent). AB stain shows acidic polysaccharides such as glycosaminoglycans in blue. (B) Residual collagen quantification on the samples at different conditions and different time points. All data are shown as mean values of $n \geq 3$ with st. dev. 
Following the mechanical and biological characterization of decellularized dehydrated scaffolds, we performed biocompatibility assays to prove that no cytotoxic degradation products were released during the storage. These assays were also necessary to investigate the capability of the dehydrated matrices to support cell adhesion and culture in cell repopulation experiments. At first, disks of esophagi stored at different time points were rehydrated and incubated with cell culture media for $24 \mathrm{~h}$ (Suppl. Fig. 3). This medium was then used to culture hBMMSCs. Nontreated control scaffold conditioned medium did not allow any cell survival as demonstrated by absence of cells at $48 \mathrm{~h}$ of culture (Fig. 4A), while dried stored samples did not affect the medium quality. Non-treated control samples could cause the release of some toxic compounds from the decellularization procedure that were not completely removed with conventional washing treatment, possibly due to the tissue thickness. Another hypothesis might be ascribed to a deterioration of the scaffold during the storage in PBS (at least 10 days from harvest/cell culture experiments). On the other hand, any potential toxic molecule was extracted and washed by the ethanol/supercritical $\mathrm{CO}_{2}$ process, and the deterioration is inhibited in the dried state. Quantification of the live/dead assay was also performed and compared to control cells, cultured in non-conditioned media, calculating the ratio of dead cells over total cells per well, resulting in high cell survival in conditioned medium during all time points (Suppl. Fig 4A-B). Secondly, the disks of esophageal tissue were used as scaffolds for $3 \mathrm{D}$ culture to verify direct cytotoxicity, capacity of cellular adhesion in the stored ECM, and promotion of cell proliferation. No or few cells adhered and proliferated during the 10 days of expansion on non-treated control scaffolds, confirming what previously observed with conditioned media. On the other hand, cells adhered and proliferated on the scaffolds stored at the different time points (Fig. 4B). To better visualize the adhesion of the mesenchymal stem cells on the scaffolds, sections of tissue were stained for f-actin, which showed the superficial adhesion and cell spreading on the luminal side of the scaffolds (Suppl. Fig 4C). 
A
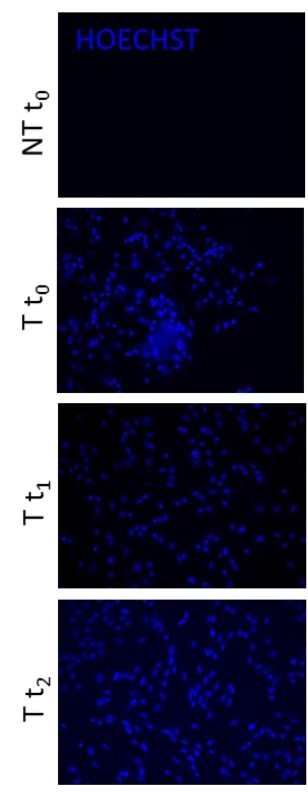
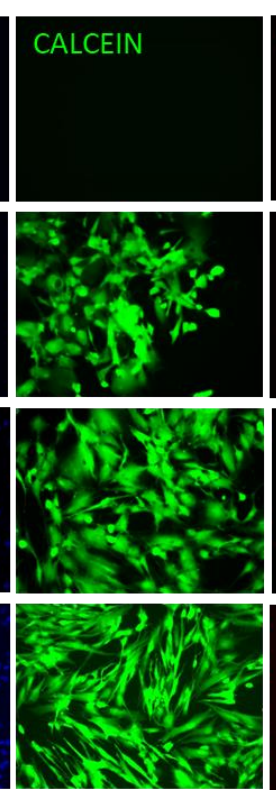
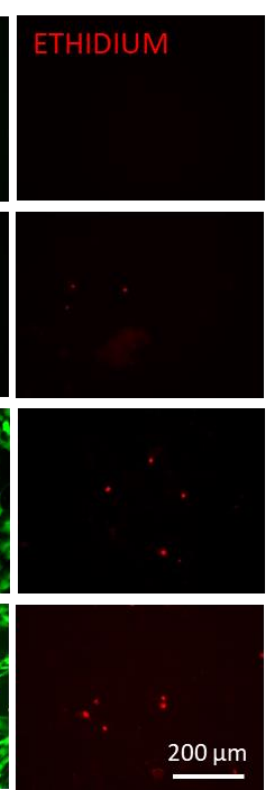

B
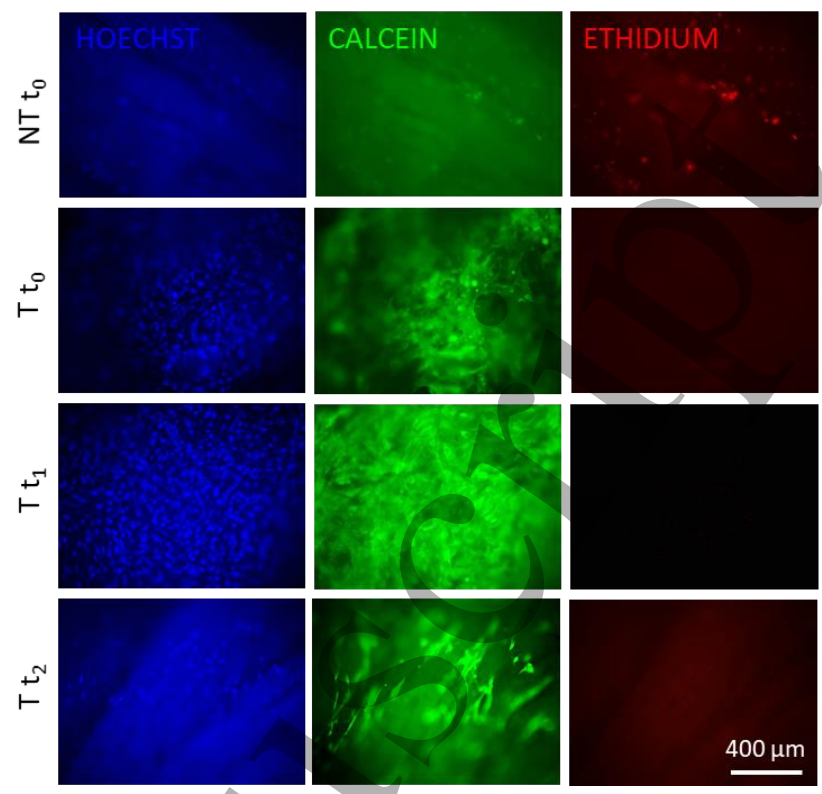

Figure 4: (A) Cytotoxicity live/dead analysis of hBMMSCs at 48h of culture using conditioned media from scaffolds stored at different time points. Fluorescence analysis shows cell nuclei marked with hoechst (in blue), live cells marked with calcein-AM (in green) and dead cells marked with ethidium homodimer-1 (in red). (B) Live and dead analysis on the sample surface. Live and dead images at $48 \mathrm{~h}$ of culture on the surface of scaffolds from different storage time points. $\mathrm{T}$ t 0 refers to the treated sample at time $0, \mathrm{~T}$ t 1 refers to the treated sample at 3 months from the process, $\mathrm{T} t 2$ refers to the treated sample at 6 months from the process, NT t0 is the control as not treated sample at time 0 . In blue is stained the nuclei with hochst, in red is stained dead cells with ethidium, in green is stained the cytoplasm of live cells.

\section{DISCUSSION}

When a patient has an ultimate organ failure, the only option available is organ transplant. Yet, transplantable organs shortage and long waiting lists are the major problems in the field [34], together with the limited survival time of vital organs after donor explants [35]. For this reason, recellularized organs are a desirable perspective in the field of allogeneic transplants.

To this end, we developed a method for dehydrating, sterilizing and storing tissues for preservation over time. In this work we applied ethanol and supercritical carbon dioxide to dehydrate sections of porcine esophagus to be stored for 3 and 6 months after processing. Dehydration method was optimized with the combination of both EtOH/SC-CO $2(10 \mathrm{MPa}$ and $35^{\circ} \mathrm{C}$ ) since $\mathrm{SC}-\mathrm{CO}_{2}$ alone was not sufficient to obtain cytocompatible scaffolds, as previously 
described by our group [30]. This procedure was sufficient for complete removal of cytotoxic residues from the decellularization process, together with complete ethanol and water elimination from the decellularized esophagi [36]. Moreover, the process was able to eliminate any form of contaminating bacteria, yeasts or molds, thus to guaranty a highly sterile scaffold for clinical application. Given the absence in humidity, scaffolds can be stored at low temperatures with no risks of re-contamination, and no risk of water crystals formation, which could eventually disrupt the ECM structure.

Supercritical drying generated a scaffold with preserved mechanical properties, similar to control, over time. Being the esophagus one active organ in the food motility, robustness of the structure a critical key feature for clinical application of tissue engineered organs, as tissue fragility can lead to graft rupture or anastomotic adverse events after implantation. We observed preserved mechanical properties at 3 and 6 months' storage, namely transyersal strength, a slightly increased longitudinal strength compared to non-treated samples, and similar longitudinal and transversal strain at break. Standard deviations observed in both controls and treated samples were within the extent of biological variability, given by the sex of the animals, age and weight range, which inevitably influence dimension and mechanical characteristics of the esophagi.

Mechanical properties strictly depend on the quality of the ECM, which needs to be preserved during decellularization [18,19] and supercritical drying [30] processes. The EtOH/SC$\mathrm{CO}_{2}$ treatment generated a dried scaffold with no visible histological damages at ECM structural level. During the long-term storage at $\mathrm{t}_{1}$ and $\mathrm{t}_{2}$, we did not appreciate any visible change in the ECM structure. All the histological analyses confirmed what already observed at mechanical level. Good conservation of collagen, keratin and glycosaminoglycans was highlighted throughout the six months of dry storage. Moreover, the muscle matrix structure and fiber disposition in the tissue showed a remarkable degree of preservation at the different time points. These characteristics are essential in the view of cellular re-population experiments, where cell adhesion, survival (absence of tissue cytotoxicity), differentiation, proliferation and functionality are strictly required. 
To this end, we verified the degree of cytotoxicity of the dried scaffolds at different time points. It is known how even small amount of residual detergents in decellularized scaffolds compromises the re-population process $[37,38]$. Infinitesimal amounts of detergent could remain in the scaffolds even after washing, due to the difficulty in cannulating and perfusing the organ, or to the intrinsic ECM complexity. The combined treatment with EtOH and continuous flow of supercritical $\mathrm{CO}_{2}$ was able to remove any toxic residual derived from the decellularization process, or from the initial degradation of the ECM that begins soon after decellularization, during the first days of tissue storage before drying treatment. Delicate primary cells, such as mesenchymal stem cells, growing in scaffold-derived conditioned media indicated biocompatibility of the tissue. On the other hand, the capacity of cell adhesion and expansion, tested with a 10 days' 3D culture experiment, provided information of the quality of the ECM. Preservation of adhesion foci, integrin sites and tissue specific epitopes after long-term storage is essential to support adhesion and differentiation into tissue specific subtypes of epithelial, muscle, endothelial, mesenchymal and neuronal precursors, when re-population experiments are required prior to transplantation.

It has to be emphasized that the tissue desiccation process that we described successfully acted as both long-term storage technique and high grade sterilization method. This outcome, previously shown for other applications [39-41], has now been proved also in tissue engineering. Previous works have shown how different sterilization methods, commonly used for clinical application, such as gamma irradiation, when applied to biological tissues at low dosage can increase tissue stiffness, while at high dosage can alter and damage the composition of the ECM $[38,42,43]$. Being decellularized scaffolds composed of defined macromolecules, their structure can be altered by radiation causing free radicals and chemical bonds breakage. These techniques compromise the sterility and long-term maintenance of scaffolds to be used in clinical application. On the other hand, our approach of using the supercritical gas for esophageal tissues was able to sterilize and allow long-term conservation for translational and clinical studies. 


\section{CONCLUSIONS}

A bank of dried decellularized organs and tissues readily accessible to laboratories and medical équipes would be greatly beneficial to the development of new successful therapies. In a context of emergency operations, medical staffs would have access to a set of sterile organs ready to be rehydrated and repopulated with autologous or heterologous cells, just days before planned organ or tissue transplants.

Taking advantage of $\mathrm{SC}-\mathrm{CO}_{2}$ drying process, we obtained a dry decellularized scaffold that could be used for the development of organ/tissue substitution procedures. The method that we proposed has a double desirable effect on the decellularized porcine esophagi: high sterilization capacity, and high dehydration capacity, which lead to the possibility to store over time the organ, still maintaining its structural and functional characteristics.

Further studies on the sterilizing effect and long-term storage possibility given by supercritical gases applied on decellularized scaffolds and biological matrices could be a great advantage in the development of a clinical grade method to be applied in translational research.

\section{ACKNOWLEDGEMENTS}

This research was funded by Cassa di Risparmio di Trento e Rovereto (CaRiTRo) within the project "Supercritical decellularization of engineered tissues for clinical application", biomedical science section, 2013. PDC is supported by NIHR Professorship and the Catapult Cell Therapy, UK. N.M.P. is supported by the European Commission H2020 under the Graphene FET Flagship (WP14 "Polymer Composites" No. 696656) and under the FET proactive ("Neurofibres" No. 732344). LU was supported by NIHR and the OAK Foundation. NE thanks Lorenza Lazzari for the donation of hBMMSCs from the Cell Factory Bank (Milan-Italy). SS thanks Filippo Michelino for carrying out the microbial analyses. 
Bibliography

[1] Pinheiro, P. F. M., e Silva, A. C. S., \& Pereira, R. M. (2012). Current knowledge on esophageal atresia. World journal of gastroenterology: WJG, 18(28), 3662.

[2] Spitz L,KielyE,PierroA.Gastric transposition in children-a 21-year experience. J PediatrSurg. 2004;39(3):276-281 [discussion276-81].

[3] Ferlay J, Soerjomataram I, Dikshit R, Eser S, Mathers C, Rebelo M, Parkin DM, Forman D, Bray F. Cancer incidence and mortality worldwide: sources, methods and major patterns in GLOBOCAN 2012. Int J Cancer. 2015 Mar 1;136(5):E359-86

[4] Gupta, B., \& Kumar, N. (2017). Worldwide incidence, mortality and time trends for cancer of the oesophagus. European Journal of Cancer Prevention, 26(2), 107-118

[5] Njei, B., McCarty, T. R., \& Birk, J. W. (2016). Trends in esophageal cancer survival in United States adults from 1973 to 2009: a SEER database analysis. Journal of gastroenterology and hepatology, 31(6), 1141-1146.

[6] Cowie, A., Noble, F., \& Underwood, T. (2014). Strategies to improve outcomes in esophageal adenocarcinoma. Expert review of anticancer therapy, 14(6), 677-687.

[7] Rouvelas I, Zeng W, Lindblad M, Viklund P, Ye W, Lagergren J. Survival after surgery for oesophageal cancer: a population-based study. Lancet Oncol 2005; 6: 864-870.

[8] Hamza, A. F. (2009, February). Colonic replacement in cases of esophageal atresia. In Seminars in pediatric surgery (Vol. 18, No. 1, pp. 40-43). Elsevier.

[9] Aramwit, P., Motta, A., \& Kundu, S. C. (2017). Tissue Engineering: From Basic Sciences to Clinical Perspectives. BioMed Research International, 2017.

[10] Lee, E., Milan, A., Urbani, L., De Coppi, P., \& Lowdell, M. W. (2017). Decellularized material as scaffolds for tissue engineering studies in long gap esophageal atresia. Expert opinion on biological therapy, 17(5), 573-584.

[11] M. Watanabe, K. Sekine, Y. Hori, Artificial esophagus with peristaltic movement, ASAIO J. 51 (2) (2005) 158161

[12] J.D. Fryfogle, G.A. Cyrowski, D. Rothwell, G. Rheault, T. Clark, Replacement of the middle third of the esophagus with a silicone rubber prosthesis: an experiment and clinical study, Dis. Chest 43 (5) (1963) 464-475

[13] Saverio La Francesca, Johnathon M. Aho, Matthew R. Barron, Ellen W. Blanco, Sherif Soliman, Lena Kalenjian, Ariel D. Hanson, Elisaveta Todorova, Matthew Marsh, KaLia Burnette, Harout DerSimonian, Robert D. Odze \& 
Dennis A. Long-term regeneration and remodeling of the pig esophagus after circumferential resection using a retrievable synthetic scaffold carrying autologous cells. Scientific Reports, 8(1), 4123, 2018

[14] Y. Takimoto, T. Nakamura, M. Teramachi, T. Kiyotani, Y. Shimizu, Replacement of long segments of the esophagus with a collagen-silicone composite tube, ASAIO J. 41 (1995) M605-M608.

[15] Y. Yamamoto, T. Nakamura, Y. Shimizu, K. Matsumoto, Y. Takimoto, Y. Liu, H. Ueda, T. Seikine, N. Tamura, Intrathoracic esophageal replacement with a collagen sponge-silicone double layer tube: evaluation of omental-pedicle wrapping and prolonged placement of an inner stent, ASAIO J. 46 (2000) 734-739

[16] Ozeki M, Narita Y, Kagami H, Ohmiya N, Itoh A, Hirooka Y, Niwa Y, Ueda M, Goto H. Evaluation of decellularized esophagus as a scaffold for cultured esophageal epithelial cells. J Biomed Mater Res A. 2006 Dec $15 ; 79(4): 771-8$

[17] Ackbar R, Ainoedhofer H, Gugatschka M, Saxena AK. Decellularized ovine esophageal mucosa for esophageal tissue engineering. Technol Health Care. 2012;20(3):215-23

[18] G. Totonelli, P. Maghsoudlou, F. Georgiades, M. Garriboli, K. Koshy, M. Turmaine, M. Ashworth, N.J. Sebire, A. Pierro, S. Eaton, P. De Coppi. Detergent enzymatic treatment for the development of a natural acellular matrix for oesophageal regeneration, Pediatr. Surg. Int. 29 (2013) 87-95

[19] Urbani L, Maghsoudlou P, Milan A, Menikou M, Hagen MK, Totonelli G, Camilli C, Eaton S, Burns A, Olivo A, De Coppi P. Long-term cryopreservation of decellularised oesophagi for tissue engineering clinical application. PLoS One. 2017; 12(6): e0179341.

[20] Rosario DJ, Reilly GC, Ali Salah/E, Glover M, Bullock AJ, Macneil S. Decellularization and sterilization of porcine urinary bladder matrix for tissue engineering in the lower urinary tract. Regen Med. 2008 Mar;3(2):145-56

[21] Jackson DW, Windler GE, Simon TM. Intraarticular reaction associated with the use of freeze-dried, ethylene oxide-sterilized bone-patella tendon-bone allografts in the reconstruction of the anterior cruciate ligament. Am J Sports Med. 1990 Jan-Feb;18(1):1-10

[22] Briganti E, Al Kayal T, Kull S, Losi P, Spiller D, Tonlorenzi S, Berti D, Soldani G. The effect of gamma irradiation on physical-mechanical properties and cytotoxicity of polyurethane-polydimethylsiloxane microfibrillar vascular grafts. J Mater Sci Mater Med. 2010 Apr;21(4):1311-9

[23] Uriarte JJ, Nonaka PN, Campillo N, Palma RK, Melo E, de Oliveira LVF, Navajas D, Farré R. Mechanical properties of acellular mouse lungs after sterilization by gamma irradiation. J Mech Behav Biomed Mater. 2014 Dec;40:168-177

[24] Sun WQ, Leung P. Calorimetric study of extracellular tissue matrix degradation and instability after gamma irradiation/Acta Biomater. 2008 Jul;4(4):817-26 
[25] Matuska AM, McFetridge PS. The effect of terminal sterilization on structural and biophysical properties of a decellularized collagen-based scaffold; implications for stem cell adhesion. J Biomed Mater Res B Appl Biomater. 2015 Feb;103(2):397-406

[26] Dominic M. Casali, Rachel M. Handleton, Tarek Shazly, Michael A. Matthews. A novel supercritical CO2-based decellularization method for maintaining scaffold hydration and mechanical properties. The Journal of Supercritical Fluids. Jan 2018, Vol 131: Pages 72-81

[27] Bernhardt, A., Wehrl, M., Paul, B., Hochmuth, T., Schumacher, M., Schütz, K., \& Gelinsky, M. (2015). Improved sterilization of sensitive biomaterials with supercritical carbon dioxide at low temperature. PloS one, 10(6), e0129205.

[28] Hennessy RS, Jana S, Tefft BJ, Helder MR, Young MD, Hennessy RR, Stoyles NJ, Lerman A. Supercritical carbon dioxide-based sterilization of decellularized heart valves. JACC Basic Transl Sci. 2017 Feb;2(1):71-84

[29] Jenna L. Balestrini, Angela Liu, Ashley L. Gard, Janet Huie, Kelly M.S. Blatt, Jonas Schwan, Liping Zhao, Tom J. Broekelmann, Robert P. Mecham, Elise C. Wilcox, and Laura E. Niklason. Sterilization of Lung Matrices by Supercritical Carbon Dioxide. Tissue Eng Part C Methods. 2016 Mar 1; 22(3): 260-269

[30] A. Zambon, M. Vetralla, L. Urbani, M.F. Pantano, G. Ferrentino, M. Pø̋zobon, N.M. Pugno, P. De Coppi, N. Elvassore, S. Spilimbergo. Dry acellular oesophageal matrix prepared by supercritical carbon dioxide, J. Supercrit. Fluids 115 (2016) 33-41

[31] Ferrentino G, Balzan S, Spilimbergo S. Optimization of supercritical carbon dioxide treatment for the inactivation of the natural microbial flora in cubed cooked ham. Int J Food Microbiol. 2013 Feb 15;161(3):189-96

[32] Hill, R. C., Calle, E. A., Dzieciatkowska, M., Niklason, L. E., \& Hansen, K. C. (2015). Quantification of extracellular matrix proteins from a rat lung scaffold to provide a molecular readout for tissue engineering. Molecular \& Cellular Proteomics, 14(4), 961-973.

[33] Mazza, Giuseppe, et al. "Decellularized human liver as a natural 3D-scaffold for liver bioengineering and transplantation." Scientific reports 5 (2015): 13079.

[34] Abouna GM. Organ shortage crisis: problems and possible solutions. Transplant Proc. 2008 Jan-Feb;40(1):34-8

[35] Edgardo E. Guibert, Alexander Y. Petrenko, Cecilia L. Balaban, Alexander Y. Somov, Joaquín V. Rodriguez, Barry J. Fullerc. Organ Preservation: Current Concepts and New Strategies for the Next Decade. Transfus Med Hemother. 2011 Apr; 38(2): 125-142

[36] Michelino, F., Gebrekidan, M. T., Zambon, A., Vetralla, M., Braeuer, A. S., \& Spilimbergo, S. (2017). In situ Raman-analysis of supercritical carbon dioxide drying applied to acellular esophageal matrix. The Journal of Supercritical Fluids, 128, 194-199. 
[37] Keane TJ, Swinehart IT, Badylak SF. Methods of tissue decellularization used for preparation of biologic scaffolds and in vivo relevance. Methods. 2015 Aug;84:25-34

[38] Rieder E, Kasimir MT, Silberhumer G, Seebacher G, Wolner E, Simon P, Weigel G. Decellularization protocols of porcine heart valves differ importantly in efficiency of cell removal and susceptibility of the matrix to recellularization with human vascular cells. J Thorac Cardiovasc Surg. 2004 Feb;127(2):399-405

[39] Sikin AM, Rizvi SS. Recent patents on the sterilization of food and biomaterials by supercritical fluids. Recent Pat Food Nutr Agric. 2011 Sep;3(3):212-25

[40] Q.Q. Qiu, P. Leamy, J. Brittingham, J. Pomerleau, N. Kabaria, J. Connor. Inactivation of bacterial spores and viruses in biological material using supercritical carbon dioxide with sterilant. J Biomed Mater Res B Appl Biomater, $91(2)$ (2009), pp. 572-578

[41] Ivan Donati, Monica Benincasa, Marie-Pierre Foulc, Gianluca Turco, Mila Toppazzini, Dario Solinas, Sara Spilimbergo, Ireneo Kikic, and Sergio Paoletti. Terminal Sterilization of BisGMA-TEGDMA Thermoset Materials and Their Bioactive Surfaces by Supercritical CO2. Biomacromolecules, 2012, 13 (4), pp 1152-1160

[42] Peter M. Crapo, Thomas W. Gilbert, and Stephen F. Badylak. An/overview of tissue and whole organ decellularization processes. Biomaterials. 2011 Apr; 32(12): 3233-3243

[43] Gouk SS, Lim TM, Teoh SH, Sun WQ. Alterations of human acellular tissue matrix by gamma irradiation: histology, biomechanical property, stability, in vitro cell repopulation, and remodeling. J Biomed Mater Res B Appl Biomater. 2008 Jan;84(1):205-17 